\title{
The Research on the Microstructure and Electrical Properties of Nb2O5 Doped PBSFCZT Ceramics
}

\author{
Jia-Qiang HAN ${ }^{a}$, De-Yi ZHENG ${ }^{b, *}$, Wen-Yin $Z_{H A O}^{c}$, Yong-Song HUANG \\ College of Materials and Metallurgy, GuiZhou University, GuiYang, 550025, China \\ a1084747691@qq.com, bzhengdeyi@hotmail.com, ${ }^{\mathrm{c}} 1830034621 @ q q . c o m$ \\ ${ }^{*}$ Corresponding author
}

Keywords: Polynary System Piezoelectric Ceramic, Nb Doped, Microstructur, Electrical Properties.

\begin{abstract}
In order to improve the electrical properties of PZT piezoelectric ceramic material, the effect of sintering temperature on the microstructure and electrical properties of the $\mathrm{Nb}_{2} \mathrm{O}_{5}$ doped PBFSZT ceramic material. The crystalline phase and microstructure of the PBSFCZT $+0.5 \% \mathrm{Nb} 2 \mathrm{O} 5$ ceramic were analyzed at the different sintering temperatures $\left(1120^{\circ} \mathrm{C}, 1150^{\circ} \mathrm{C}, 1180^{\circ} \mathrm{C}\right.$ and $\left.1210^{\circ} \mathrm{C}\right)$ by $\mathrm{x}$-ray diffraction (XRD) and scanning electron microscopy (SEM) respectively. The results of the experiment show that the amounts of the $\mathrm{Nb} 2 \mathrm{O} 5$ was $0.5 \%$, the grain size of the PBSFCZT piezoelectric ceramic materials decreased correlated with the increasing of the sintering temperature. When the sintering temperature at $1180^{\circ} \mathrm{C}$, the grain growths well and the grain-boundary intersection in tight, an excellent comprehensive electrical properties of the PBSZT ceramics material are as follows : $\varepsilon=3626, \tan \delta=1.7, \mathrm{~d} 33=478 \mathrm{PC} / \mathrm{N}, \mathrm{Kp}=0.669$. These results proved that appropriate softness doping can decrease the sintering temperature and improve the piezoelectric properties of the PBSFCZT ceramic material.
\end{abstract}

\section{Introduction}

With the development of the high technology, the different country researchers focus on the new material technology. Since 1942, the first piezoelectric ceramic $\mathrm{BaTiO}_{3}$ has been invented, the research on the piezoelectric ceramic become more and more important. Because of the good mechanical properties and reliability piezoelectric properties of the piezoelectric ceramics, it has been regard as an important mechanical, heat, light senstive function material. It has been widely used in the sensors, acoustic transducer, micro-displacement device and other electric components, etc $[1,2]$. In present, there are two major methods to improve the properties of the piezoelectric ceramics: one is conventional mixture oxide doping, another one is technology improvement. In this paper, the effect of the sintering temperature on the microstructure and properties of $\mathrm{Nb}_{2} \mathrm{O}_{5}$ doped PBSFCZT ceramics has been researched.

\section{Experimental Procedures}

In this experiment, the $\mathrm{Pb} 1-\mathrm{xBax}[(\mathrm{Sb} 1 / 2 \mathrm{Fe} 1 / 2) 1 / 2 \mathrm{Ca} 1 / 2] 0.02(\mathrm{Zr} 53 \mathrm{Ti} 47) 0.98+0.5 \% \mathrm{Nb} 2 \mathrm{O} 5$ are prepared by a conventional mixed oxide sintering method.The reagent grade raw powders of $\mathrm{Pb} 3 \mathrm{O} 4$, $\mathrm{BaCO} 3, \mathrm{Sb} 2 \mathrm{O} 3, \mathrm{Fe} 2 \mathrm{O} 3, \mathrm{ZrO} 2, \mathrm{TiO} 2, \mathrm{Nb} 2 \mathrm{O} 5, \mathrm{CaCO} 3$ are used as starting materials. And then the powders are weighed according to stoichiometric ratio. The powders mixed by ball milling for 16 hours with $99 \%$ alcohol. After ball milling, the mixture is pre-sintered at $860^{\circ} \mathrm{C}$ for 4 hours. After that, the obtained oxide powder was ball milling again.After complete the previous processes, the powder was formed into $\varnothing 12.88 \mathrm{~mm} \times 1.2 \mathrm{~mm}$ plates with $7 \mathrm{wt} \%$ paraffin. Then the plates were subjected to a process of debinding at $700{ }^{\circ} \mathrm{C}$ for 500 minutes and then sintered at $1120 \mathrm{oC}, 1150 \mathrm{oC}$, $1180 \mathrm{oC}$ and $1210 \mathrm{oCf}$ or $2 \mathrm{~h}$ respectively. Finally, the ceramic plates are coated with sliver electrodes on both sides and polarized at 75 oCin silicon oil bath by applying DC electric fields at $2.3 \mathrm{KV} / \mathrm{mm}$ for $30 \mathrm{~min}$. The polarized ceramic plates are then tested with dielectric loss $(\tan \delta)$, electromechanical coupling coefficient $(\mathrm{kp})$, piezoelectric constant $(\mathrm{d} 33)$ and dielectric constant $(\varepsilon)$ after aging at room temperature for $24 \mathrm{~h}$. 
The phase structure of the samples was analyzed by X-ray diffraction(XRD) and the fractured surface were observed by scanning electron microscopy(SEM). The piezoelectric constant d33 was measured by quasi-static d33 meter(ZJ-6A,China).The electromechanical coupling coefficient Kp and the electromechanical quality factor Qm were calculated from the resonance and antiresonance frequencies using precise impedance analyzer(HP4194, Angilent).

\section{Results and Discussion}

\section{Analysis of Electrical Properties}

The electrical properties (dielectric loss $(\tan \delta)$, electromechanical coupling coefficient $\left(\mathrm{K}_{\mathrm{p}}\right)$, piezoelectric constant $\left(\mathrm{d}_{33}\right)$ and dielectric constant $\left.(\varepsilon)\right)$ of PBSFCZT samples with the sintering temperature changed from $1120^{\circ} \mathrm{C}$ to $1210^{\circ} \mathrm{C}$ for $2 \mathrm{~h}$ are listed in Tab.1.

Tab. 1 The electric properties of PBSFCZT samples sintered at $1120^{\circ} \mathrm{C}--1210^{\circ} \mathrm{C}$

\begin{tabular}{ccccccccc}
\hline Samples & Temperature & $\mathrm{c}$ & $\varepsilon$ & $\mathrm{f} 1$ & $\mathrm{f} 2$ & $\mathrm{kp}$ & $\mathrm{d} 33$ & $\tan \delta$ \\
\hline 1 & $1120^{\circ} \mathrm{C}$ & 2346 & 5646 & 181.1 & 235.2 & 0.723 & 652 & 1.6 \\
\hline 2 & $1120^{\circ} \mathrm{C}$ & 1192 & 2915 & 183.9 & 234.2 & 0.701 & 426 & 1.8 \\
\hline 3 & $1150^{\circ} \mathrm{C}$ & 1457 & 3231 & 180.8 & 227.3 & 0.686 & 467 & 1.6 \\
\hline 4 & $1180^{\circ} \mathrm{C}$ & 1602 & 3625 & 182.8 & 226.6 & 0.669 & 478 & 1.7 \\
\hline 5 & $1210^{\circ} \mathrm{C}$ & 1498 & 3194 & 182.8 & 220.8 & 0.634 & 438 & 1.7 \\
\hline
\end{tabular}

From the Tab.1, it has been found that the samples of the PBSZT ceramics have the same electrical properties when sintered at the same temperature. But when the samples sintered at $1120^{\circ} \mathrm{C}$, there is some difference in the samples, sample 1 have an good electric properties, the sample 1 posses the satisfied electrical properties not only in the dielectric loss, electromechanical coupling coefficient, piezoelectric constant and dielectric constants, which are as follows: $\tan \delta=1.8 \% \mathrm{Kp}=0.723, \mathrm{~d} 33=652 \mathrm{pC} / \mathrm{N}, \varepsilon=5646$, the electrical properties higher than other samples about 30\%. The electrical properties of the samples gradually improving with the sintering temperature increased. When the samples sintered at $1180^{\circ} \mathrm{C}$, the PBSFCZT samples have an good electrical properties: $\tan \delta=1.7 \% \mathrm{Kp}=0.669, \mathrm{~d} 33=478 \mathrm{pC} / \mathrm{N}, \varepsilon=3625$.

\section{Analysis of XRD}

Fig. 1 shows the X-ray diffraction (XRD) patterns of PBFSZT doped $0.5 \% \mathrm{Nb}_{2} \mathrm{O}_{5}$ ceramic samples at different sintering temperature $\left(1120^{\circ} \mathrm{C}, 1150{ }^{\circ} \mathrm{C}, 1180{ }^{\circ} \mathrm{C}\right.$ and $\left.1210^{\circ} \mathrm{C}\right)$ for $2 \mathrm{~h}$.
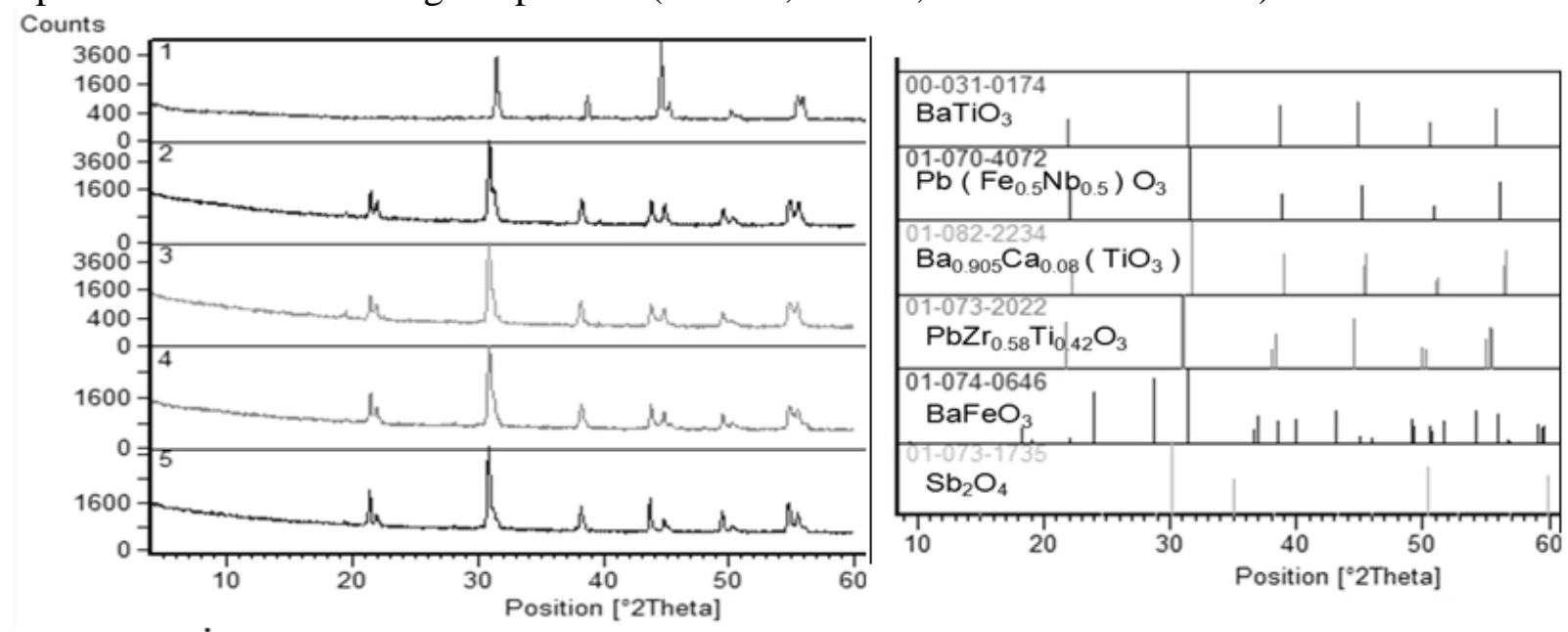

Fig.1 The XRD images of the PBSFCZT samples from 1 to 5

It can be found from the Fig.1, a comparative pure perovskite structure was obtained, but at the same time some pyrochlephases were found. From the samples 2 to 5 , there are some BT, PFN, 
$\mathrm{PZT}, \mathrm{BCT}, \mathrm{BF}$ and $\mathrm{Sb}_{2} \mathrm{O}_{4}$ phases.But different from the the other samples, the sample 1 has no obvious double diffraction peak around the $21^{\circ}$, this is because the sample 1 has no BF phase exist.But the diffraction peak of the secondary phase gradually disappeared with the increased of the sintering temperatures, the electrical properties of the sample will become better[3,4].The scanning regions range from $10^{\circ}$ to $60^{\circ}$.

\section{Analysis of SEM}

Fig. 2 is the SEM photography of the PBSFCZT doped $0.5 \% \mathrm{Nb}_{2} \mathrm{O}_{5}$ ceramic samples sintered at different sintering temperatures $\left(1120^{\circ} \mathrm{C}, 1150^{\circ} \mathrm{C}, 1180^{\circ} \mathrm{C}\right.$ and $\left.1210^{\circ} \mathrm{C}\right)$.
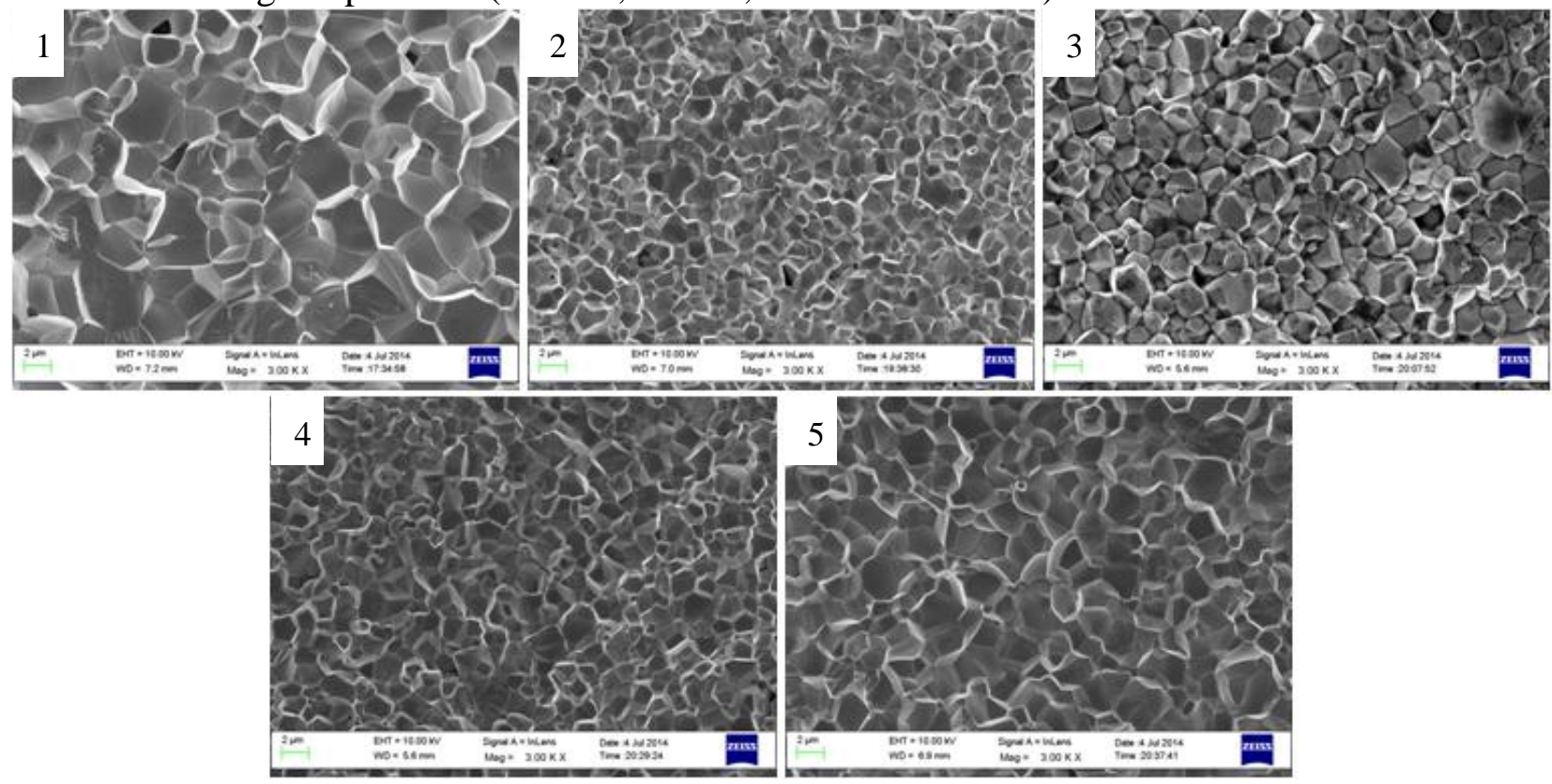

Fig. 2 The SEM images of the PBSFCZT samples from 1 to 5

From the Fig.2, it can be seen that the grain size of sample 1 is obvous bigger than other samples. The grains size of the ceramic sample from 2 to 5 have a significant change with the sintering temperature vary from $1120^{\circ} \mathrm{C}$ to $1210^{\circ} \mathrm{C}$, the grain size of the samples increased with the increasing of the sintering temperature. Sample 5 exhibit the largest grain size and are over developed when sintered at $1210^{\circ} \mathrm{C}$. Wang xiaohui et al[5] research shows that, with the size of grain change, the cell parameters also change related to grain size. Furthermore,that will influence the electric properties of the samples.Experiment results shows that,when sintered at $1180^{\circ} \mathrm{C}$, grains grows well, the intersection between grain and grain combined well, there is no segregation phase appearance. Correlated to electrical properties results, the sintering temperature have an obvious influence on the piezoelectric ceramic.With the increasing of sintering temperature, the electric properties first increased but after gradually decrease. The Nb2O5 doped in PBSFCZT samples which can make the samples sintered easier[6]. The decrease of grain size can cause the increase of dielectric constant of samples. The reason of sample 1 have an excellent comprehensive electrical properties, because of the sample in the sintering furnace location is not same, which contribute to the obvious difference.

\section{Conclusion}

The influences of different sintering temperatures on the microstructures and the electrical properties of the PBSFCZT doped $0.5 \% \mathrm{Nb}_{2} \mathrm{O}_{5}$ ceramic samples are investigated. In this paper, it has been observed that, different sintering temperatures will influence the grain size and electrical properties of the PBSZT doped $0.5 \% \mathrm{Nb}_{2} \mathrm{O}_{5}$ ceramic samples respectively. Through appropriate adjustment of the sintering temperature, the grains size of the PBSZT ceramic samples materials will become fine and the porosity of the bulk material will decrease.when the sintering temperature 
is $1180^{\circ} \mathrm{C}$, both the electromechanical coupling coefficient and the piezoelectric constant of samples will be improved, which are as follows: $\tan \delta=0.017, \mathrm{kp}=0.669, \mathrm{~d} 33=478 \mathrm{pC} / \mathrm{N}, \varepsilon=3626$.

\section{Acknowledgements}

This work was financially supported by the Training Programs of Innovation and Entrepreneurship for Undergraduates.

\section{References}

[1]Xiaojuan Li,Quanlu Li,Miaoxia Xie et al.New developments and new applications of the Piezoelectric ceramics at home and abroad.Bulletin of the Chinese Ceramic Society, 2006, 25(4).

[2]A. Moulson, J. Herbert, in: Electroceramics: material, properties, applications, John Wiley \& Sons Inc (2003).

[3]D. Zheng, J. Swingler, P. Weaver, in: Current Transients in Ferroelectric Ceramics under Conditions of High Humidity, Sensors \& Actuators: A. Physical Vol. 151-1 (2010), p. 106.

[4]D. Zheng, J. Swingler, P. Weaver, in: Voltage - Electrical Conduction Mechanisms in Piezoelectric Ceramics under Harsh Operating Conditions, Sensors \& Actuators: A. Physical Vol. 167-1 (2011), p. 19.

[5]Wang xiaohui et al. Journal of Functional materials [J],1996, 27(3):261.

[6]C. L. Cheon, H. G. Lee, in: The piezoelectric properties and the stability of the resonant frequency in $\mathrm{Mn}-\mathrm{Cr}$ Co-doped PSZT ceramics, Journal of Materials Science: Materials in Electronics Vol. 10-2 (1999), p. 81. 